Revista Iberoamericana, Vol. LXX, Núm. 207, Abril-Junio 2004, 431-441

\title{
EL TRUEQUE Y LA ECONOMÍA DEL DON EN TERRA NOSTRA DE CARLOS FUENTES
}

\author{
POR \\ Michael Abeyta \\ Colorado State University
}

En la obra de Carlos Fuentes titulada Cervantes, o la crítica de la lectura, encontramos una guía crítica que nos encamina a trazar la relación entre economía y escritura en la novela Terra Nostra, del mismo Fuentes, y que sugiere una interpretación que podría relacionarse con las teorías de los críticos Georges Bataille y Jacques Derrida. En el presente artículo examinaré la función en Terra Nostra de lo que Fuentes llama "la economía del don”. Por lo general, esta novela emplea conceptos económicos como éste para indagar la relación entre lenguaje, economía y poder en la literatura; a saber: las metáforas de la usura, el trueque, el don y el sacrificio generan la narración y determinan la manera en que se representan y se deconstruyen las manipulaciones del poder en la novela. Entre estas metáforas y conceptos, la economía del don es la que más define la estructura de la novela y la que más determina la relación entre lector y autor. Pero antes de indagar en la funcion del don en la novela cabe examinar cómo Fuentes ha concebido la idea del don a partir de su lectura de la teoría de Georges Bataille.

El concepto de la economía general de Bataille aproxima lo que éste consideraba una ciencia que estudia los excesos de energía producidos en el universo, excesos que no pueden ser utilizados. Este desgaste inútil, o desperdicio, también implica una pérdida irreducible al nivel de la representación, lo cual supone una pérdida de significado. Como marco teórico, la economía general estudia y postula una relación con esta pérdida con respecto a otras economías que Bataille califica de "economías restringidas". Mi aproximación crítica a Terra Nostra escudriña la manera en que las economías restringidas del trueque, la acumulación y la conservación son tanto complementadas como socavadas por economías no-restringidas que funcionan a diferentes niveles de la narración. Estas son el estilo barroco de la novela, el exceso de su lenguaje figurado y la representación de sacrificios, potlatches, los regalos y otras relaciones socio-económicas.

Así que en el pensamiento de Bataille, y también en los escritos de Derrida, el don, o el regalo, se diferencia del trueque y toda economía del cambio. En el trueque, acción de permutar una cosa por otra, la reciprocidad queda implícita en el intercambio, mientras que en la economía del cambio se supone un campo más amplio que incluye el dinero como equivalente universal que sustituye las mercancías en el cambio, en la compra y la venta. “La economía del don”, como la llama Fuentes, es más problemática porque lo que se gana al presentar un regalo, muchas veces, es sólo de valor simbólico: el prestigio o poder que 
se gana con el potlatch, el sacrificio entendido como la paga de una deuda sagrada, etc. Para Derrida, el don, una vez que se piensa como tal, implica un retorno, una contrapartida y un interés, y por eso se convierte en trueque o intercambio. No obstante, la base de toda esta discusión sobre el don y el intercambio es el pensamiento de Marcel Mauss, en particular su descripción del potlatch, la cual es fundamental para la concepción de la escritura en Fuentes.

En Cervantes, o la crítica, Fuentes compara la escritura de James Joyce a un potlatch, es decir a un don de rivalidad, que rompe el "régimen tradicional de la narración”. Fuentes se refiere a Bataille para explicar el sentido y la función del "potlatch”:

Georges Bataille da cuenta de la ruptura de la economía del trueque por la del potlatch o don que crea una economía del desgaste o de la pérdida con el propósito de poner fin a la estabilidad de las fortunas dentro de la economía totémica ... El potlatch rompe el statu quo conservador y erige en su lugar un principio contrario a la conservación. (108)

“Potlatch” es palabra Chinook y aparece en "Essai sur le don” de Marcel Mauss, un estudio antropológico del fenómeno del trueque o “dons échangés” entre varias culturas, sobre todo los indígenas del noroeste de la costa pacífica (el estado de Washington y British Columbia). Según Mauss, el término potlatch significa "alimentar" o "consumir" y se refiere a las fiestas invernales que constituían la asamblea solemne de las tribus (1512). Pero en estos festivales había un principio de rivalidad y hostilidad entre los caciques que competían por el poder. Refiriéndose a estas prácticas descritas por Mauss, Bataille señaló que muchas veces el potlatch era "la destrucción solemne de bienes, ofrecidos por un cacique a su rival con el propósito de humillarlo, de desafiarlo y de obligarlo (112).

Si bien Mauss argüía también que al dar un regalo, éste era “interesado,” con la obligación de reciprocar, confundía el don o el potlatch con la reciprocidad y la circulación general de los bienes. Según Bataille, el don se anula en cuanto el receptor recibe la contrapartida, lo que excluye la comparación. Derrida ha profundizado más sobre esta cuestión; señala que Mauss describe demasiado tranquilamente el potlatch como "dones intercambiados”, sin preocuparse por la cuestión de si el don puede considerarse todavía un regalo una vez que ha sido “intercambiado”. Según Derrida:

A Mauss no le inquieta demasiado esa incompatibilidad entre el don y el intercambio, o el hecho de que un don intercambiado no sea más que un toma y daca, es decir, una anulación del don. Al subrayarlo no queremos decir que no hay don intercambiado. No se puede negar dicho fenómeno, ni aquello que presenta ese aspecto justamente fenoménico de los dones intercambiados. Lo que parece que es preciso cuestionar es, justamente, el ser-conjuntamente, el ser-al mismo tiempo, la síntesis, la simetría, la sintaxis o el sistema, el syn que articula dos procesos jurídicamente tan incompatibles como el del don y el del intercambio. (Dar (el) tiempo 44)

Derrida critica la totalización del concepto de Mauss, quien al querer elaborar el fenómeno social total del don lo confunde con el intercambio. Este punto es muy importante porque la tendencia en la crítica sobre Fuentes ha sido reducir la concepción del potlatch y la economía del don en su obra a la reciprocidad y el intercambio. Se trata 
de una totalización fácil que propone una visión metanarrativa y utópica que no corresponde a la narrativa de Fuentes y que obscurece su posición sobre la cuestión del don.

Uno de los casos más notorios de esta tendencia se encuentra en el artículo "Terra Nostra: Theory and Practice” de Roberto González-Echevarría, aparte de eso, una lectura excelente de las obras de Fuentes. Cuando critica el concepto de re-escritura en Cervantes, o la crítica y en Terra Nostra, González-Echevarría asevera que en Fuentes "if the novel reflects the fragmentation of Hispanic culture and history, Fuentes proposes a reconciliation analogous to the one he pursues between Latin America and Spain. The return to a basic set of figures and events is a demolition prior to a reconstruction that reader and writer will accomplish through a ritualistic exchange” (137). González-Echevarría no acierta en su interpretación del concepto del potlatch: al igualar el potlatch y el intercambio, o "trueque ritual”, repite el mismo error de Marcel Mauss cuando éste confundió el don y el cambio, la parte y el todo (véase también la crítica de Mauss en Lévi-Strauss, su Introduction to the Works of Marcel Mauss). Reducir el potlatch de Fuentes al "trueque ritualístico" es perder toda la riqueza de matices que se produce en las separaciones temporales entre el acto de dar, la obligación de la contrapartida y el recibir. Según Pierre Bourdieu, este tipo de totalización, u “objetivización”, desmiente y anula el lapso temporal que permite la interpretación del regalo como acto de generosidad; destruye la realidad de todas las prácticas que, como el regalo, suspenden la ley del cálculo y del interés propio (112). Estas prácticas son la labor simbólica, lo que oculta el cálculo -en una palabra, la ficción. De ahí que todo el juego entre la economía del don y el trueque en Terra Nostra y Cervantes, o la crítica determina una gran parte de la metaficción de la escritura de Fuentes. Es curioso, además, que González-Echevarría, a la vez que quisiera anular la temporalidad del potlatch, también se equivoque al dividir la deconstrucción y reconstrucción de los valores culturales, ya que en la escritura de Fuentes las dos operaciones son simultáneas. La de/reconstrucción funciona tanto durante la lectura como la escritura, sobre todo en la lectura como re-escritura. Fuentes afirma la integración y simultaneidad de estas dos operaciones cuando, al referirse a Cervantes y a Joyce, dice: "ambos pronuncian las palabras cenizas del final y las palabras llama de inicio. Ambos plantean, uno al nivel de la crítica de la lectura y el otro al nivel de la crítica de la escritura, la crítica de la creación dentro de la creación” (Cervantes, o la crítica 109).

Fuentes sigue sobre todo la concepción de la economía del don según Bataille, quien subraya que a través del potlatch el donante se apropia del poder cuando el receptor del regalo acepta el reto de la contrapartida, el de dar un regalo superior. El receptor se subordina por el endeudamiento. En Bataille, la lógica del don anula la reciprocidad; lo que se adquiere, el apoderamiento, se lleva a cabo necesariamente por medio de la pérdida y el desgaste, la destrucción o consumo inútil de lo que se ha dado (La part maudite 11315). Esta lógica tiene cierta consecuencia para la narrativa, como afirma Fuentes:

Fiesta, espectáculo, duelo, batalla, ceremonia, actividad literaria pervertida, atentado contra toda la cultura previa, contra el sujeto tradicional, contra las distinciones entre exterioridad e interioridad, bien y mal, [. . .] la escritura de Joyce es un potlatch, que rompe el régimen tradicional de la narración y modifica la norma avara del trueque entre escritor y lector, la norma colombiana del melés y teleo. Melés, telés y noslés, le dice 
Joyce al lector, te ofrezco un potlatch, una propiedad excrementicia de las palabras, derrito tus lingotes de oro verbal y los arrojo al mar y te desafío a hacerme un regalo superior al mío, que es el don asimilado a la pérdida ... (Cervantes, o la crítica 108-9)

En cuanto a Terra Nostra, el propósito de esa narración tan excesiva y barroca es el de obligarle al lector a participar en la re-escritura, no sólo de la novela, sino también de todo el legado cultural de Latinoamérica. El tono irreverente del "Melés, telés y noslés", es un juego joyceano de combinar palabras, e implica una relación desequilibrada entre lector y escritor. Un tono, además, que se repite en la narración de Terra Nostra, en donde varios de los narradores desafían de la misma manera a sus narratarios.

El comentario de Fuentes sobre el don ayuda a entender la “economía” de la escritura joyceana, sobre todo el papel del desgaste y la función como potlatch. Según Fuentes, la crítica de la escritura en la obra de Joyce comprende una crítica de la escritura individual: el autor como sujeto singular se anula; las novelas son escritas por todos y por Joyce, quienes son uno y el mismo. Esto implica que el lector tiene que ser también el autor del texto. Como en las obras barrocas la exuberancia de la escritura joyceana desafía al lector y así rompe el trueque normal y hedonista entre el lector y el escritor. Como potlatch su escritura equivale a un regalo ostentoso que le desafía al lector a producir una contrapartida superior. De este modo el regalo no conduce al trueque, o al intercambio recíproco, sino al desgaste lujoso por parte del donante y a la obligación futura para el receptor. No se lleva a cabo un cambio, sólo el desafío que no permite ninguna ilusión de reciprocidad o de simetría.

El juego y la tensión entre el don y el trueque predominan en Terra Nostra, sobre todo en la segunda parte "El mundo nuevo". Peregrino, el narrador de "El mundo nuevo", le cuenta su viaje a las Américas a Felipe, el rey de España. Asimismo, Celestina, un personaje central que se reencarna en diferentes vidas, le lleva a Peregrino a la corte para que narre al rey las noticias del nuevo mundo, con propósito de desestabilizar el orden absolutista y despótico del viejo mundo. En el transcurso de su viaje, Peregrino recibe la memoria colectiva del nuevo mundo cuando escucha la leyenda del Viejo de las Memorias. Éste, también nombrado “el guardián del pacto”, el que garantiza el pago del tributo de su pueblo al imperio azteca, le cuenta el mito de la creación al joven náufrago Peregrino y predice su papel en la leyenda. Además de eso, señala la deuda sagrada que todo ser humano le debe a la diosa madre de la tierra.

La leyenda se presenta como una dádiva más dentro de una serie de regalos. Después de contarla, el Viejo desafía a Peregrino a que compense el don de la memoria con otro regalo que renueve la alianza entre ellos.

Me miró largo tiempo con sus ojos de tristeza, negros y podridos como la selva, duros y labrados como el templo, brillantes y atesorados como el oro. Mostró mis tijeras y las movió. Dijo que me las agradecía. Yo di las tijeras. Ellos me dieron el oro. Yo di mi trabajo. El me dio la memoria.

Los ojos del anciano lanzaron una luz implacable, tan cruel como debía ser la de los ojos de la diosa madre, cuando al cabo me preguntó:

“¿Qué nos darás tú ahora?” (402) 
Esta pregunta del Viejo de las Memorias suspende la corriente narrativa y, en este momento, Peregrino deja de narrar para dirigirse directamente al narratario, a Felipe, para comentar y sumar sus experiencias en el nuevo mundo. Le dice a Felipe:

Oh Señor que hoy me escuchas, dime si después de oír cuanto aquí he contado, y sin saber aún lo que me falta por contar, entiendes como yo la verdad más verdadera de ese mundo al que mis desventuras me arrojaron, dime, pues cuanto me falta por decir no hará sino fortalecerla: que aquí todo era un trueque de vida por muerte y muerte por vida, cambio de miradas, de objetos, de existencias, de memorias, sin cesar, y con el propósito de aplacar una furia anunciada, aplazar la siguiente amenaza, sacrificar una cosa para salvar a las demás, sentirse en deuda con cuanto existe y dedicar vida y muerte a una perpetua devoción renovadora. (402-3)

En estos pasajes la tensión entre el trueque y el don queda muy marcada, precisamente porque el acto de dar no presupone un trueque ni garantiza la alianza. Así la pregunta “¿Qué nos darás tú ahora?” representa un momento de tensión y peligro porque el equilibrio establecido a través del trueque queda amenazado. Por eso los ojos del Viejo expresan crueldad. También este último pasaje representa una economía basada en el sacrificio y la deuda sagrada. En Terra Nostra, como en la cosmogonía nahua, este consumo de la vida en el sacrificio celebra la abundancia general de la vida y la naturaleza a la vez que representa una “devoción perpetua” a la renovación. Según Bataille, el sacrificio preserva y cohesiona la colectividad; para que ésta sobreviva la catástrofe, tiene que apaciguar a la muerte con la violencia, ofreciéndole una víctima. Una cosa o una persona se sacrifica para salvar a los demás. En adición, la violencia sacrificadora se asemeja a la catequesis, o a una sinécdoque: a propósito, un término se confunde por otro; una vida particular se sacrifica como la paga simbólica por una deuda que todos tienen que pagar eventualmente. Esta dilación no permite que el trueque se realice del todo, que se cumpla, y entonces prolonga la deuda sagrada como obligación que eslabona a cada individuo tanto a la comunidad como a la divinidad.

En el encuentro entre Peregrino y el Viejo el trueque no se cumple: la pregunta como desafío representa una pausa agresiva, la expectativa de que se reinicie el círculo de la deuda y la alianza. Asimismo, la aparente reciprocidad del trueque entre la vida y la muerte es engañosa; la estructura quiásmica del pasaje da cierto equilibrio al trueque ("trueque de vida por muerte y muerte por vida”), pero éste no se ha cumplido todavía entre los dos hombres. En este sentido, la pregunta del Viejo de las Memorias, “¿Qué nos darás tú ahora?”, convierte la leyenda que acaba de contar en potlatch, en un regalo que requiere su contrapartida. Al darle la memoria a Peregrino, el anciano también lo desafía a contestar con un don equivalente o superior a la leyenda. Con este fin, la pregunta vincula a Peregrino a la leyenda. Según Peregrino:

Todo lo dicho por el anciano era para mí cosa de fantasía y leyenda hasta que las palabras que me dirigía ahora me convirtieron en sujeto de esa fantasía, en prisionero de esa leyenda:

“¿Qué nos darás tú ahora?” (403) 
La pregunta convierte la leyenda en un potlatch parecido al que describe Fuentes en Cervantes, o la crítica de la lectura: “melés, telés, noslés.” La relación entre el Viejo como narrador de una leyenda y Peregrino como narratario refleja esta característica del potlatch. La leyenda del Viejo es la leyenda de un pueblo diferente (melés), en la que Peregrino escucha su propia historia (telés), y por fin, conoce su papel transformador en la leyenda, su contribución al mestizaje (noslés). Al incluir a Peregrino en la leyenda, el anciano le incita a ver el mundo nuevo y a recontar su experiencia en ese mundo tanto desde la perspectiva de un extranjero como de un nativo, tanto desde afuera como desde adentro. Como el narrador-protagonista de "El mundo nuevo," Peregrino a su vez se convierte en el narratario de la leyenda del Viejo de las Memorias. Mientras Peregrino escucha la leyenda, se da cuenta de su participación como Serpiente de Plumas (Quetzalcóatl), y luego como Espejo de Humo (Tezcatlipoca). En una inversión borgiana la leyenda absorbe a Peregrino como su héroe y su antagonista a la vez. Por otra parte, la pregunta como desafío interrumpe la corriente narrativa. La reiteración de la pregunta encuadra y suspende la reflexión del náufrago acerca del potlatch. Al mismo tiempo, acentúa la transformación que siente en el momento. Por lo general, la reiteración de la pregunta a través de "El mundo nuevo” produce el efecto de suspender y volver a empezar el tiempo narrativo.

Aun cuando Peregrino contesta el desafío del viejo al regalarle el espejo, este regalo termina el ciclo de trueques entre Peregrino y el Viejo. La contrapartida de Peregrino no es tanto el espejo mismo, sino su efecto: cuando el anciano se mira en él, le espanta la imagen inesperada de su propia vejez; no creía que le afectara el paso del tiempo porque se creía eternamente joven, inmortal. En el espejo ve la imagen de su propia muerte. El regalo del espejo anula el tiempo, tal como el Viejo lo concebía. El tiempo y la ley del Viejo de las Memorias siguen la economía del trueque, en la cual siempre se espera la compensación. Así que, en lugar de un trueque de narraciones, la contrapartida de Peregrino es un espejo que rompe el equilibrio recíproco y que asesina al Viejo. En este sentido, el espejo se opone a la narración: representa el silencio de una mirada que no se dirige a otra, ni se cambia con otra, una mirada desviada hacia adentro.

Al final de "El mundo nuevo,” cuando Peregrino se prepara para volver a España, los veinte indígenas jóvenes de habla española que él había rescatado de Mictlan, la tierra de la muerte, recuentan la serie de regalos y desafíos que Peregrino ha tenido que dar y enfrentar. El recuento de la serie ilumina más la relación entre la economía del don y la narración. Mientras ésta sigue la trayectoria de Peregrino como figura o héroe mítico, la estructura de la narración también sigue las trayectorias de los regalos. Además, podemos interpretar la narración en términos de lo que no se ha dado, de lo que se ha rechazado y también de lo que se ha robado. Las tijeras y el espejo, por ejemplo, no sólo rompen la corriente temporal de la narración, iniciando así nuevos ciclos míticos-narrativos en "El mundo nuevo”, sino que también representan “trueques” fracasados -siempre regresan a Peregrino. Cabe recordar que Peregrino los había robado antes de salir para el mundo nuevo. (Lo que es más, hay toda una economía figurada implícita en estos dos objetos: las tijeras tienen la función de dividir, de partir y también de delimitar el destino humano -moira; el espejo, por otra parte, siempre se asocia en la obra de Fuentes con las funciones 
de la multiplicidad, la repetición y la diferencia, es decir, la deconstrucción de la identidad unívoca). El recuento de regalos sirve sobre todo como un acto ritual del habla que justifica el potlatch, el regalo que no puede ser superado. También le libera a Peregrino de la obligación de aliarse con el nuevo mundo y de cumplir el destino mítico de Quetzalcoátl, el Dador de la Vida:

-Pedro dio la vida por ti.

-Tú diste las tijeras.

-Te dieron el oro.

-Tú diste tu trabajo.

-Te dieron la memoria.

-Les diste un espejo.

-Te dieron su propia muerte.

-Respondiste con amor: a ellos, muertos; a una mujer, viva.

-Ella te dio tus días.

-Los cinco días del sol te ofrecieron veinte días de tinieblas.

-Los veinte días del espejo de humo te ofrecieron a tu doble.

-Tu doble te ofreció su reino.

-Cambiaste el poder por la mujer.

-La mujer te dio la sabiduría. (492)

Según los jóvenes, el ciclo narrativo empieza con el regalo que Pedro recibe de la tierra: "La nueva tierra le dio la vida a Pedro: tu amigo culminó en ella su existencia entera, sus sueños, sufrimientos y trabajos. Su vida valió la pena. El nuevo mundo se la regaló completa” (491). Termina el ciclo con el regalo insuperable que los jóvenes a su vez le dan a Peregrino, lo cual le libera a éste del círculo de la deuda:

-Tú nos diste nuestras vidas.

-Nosotros te damos tu libertad.

- ¿Puedes hacernos una ofrenda superior? -No puedes.

-Ha culminado la historia. (492)

El regalo insuperrable de la libertad termina la "historia”; el papel de Peregrino como el Dador de la Vida se ha realizado. Los jóvenes también lo salvan de los días funestos del otro lado de su destino, de su protagonismo oculto como Espejo de Humo, la fuerza destructiva dentro del círculo ritual de la deuda. Peregrino se ve libre, entonces, para volver a España donde relata al rey la historia de sus peripecias en el nuevo mundo.

Si bien en un principio el recuento parece ser una serie de trueques, hay varias razones de por qué esto no puede ser, algunas ya las hemos mencionado. La misma pregunta y su respuesta: “-¿¿2Puedes hacernos una ofrenda superior?/ -No puedes” desmienten la idea de una relación de cambio y afirman la culminación de una serie de potlatches, de regalos y contrapartidas. Algunos de los regalos son contradictorios y reflejan el dar y recibir del potlatch (el acto de dar u ofrecer una dádiva ostentosa para apropiarse del poder sobre el receptor). Insisto en este punto porque el trueque implica el intercambio equilibrado, mientras que en los potlatches predominan relaciones de poder 
y de obligación, y en la novela en particular, reafirman la alianza con la tierra y con la colectividad. En este sentido, si pensamos en la connotación tanto económica como narrativa del recuento de los regalos, la serie se organiza en torno a la alianza con la tierra, en particular al "nuevo mundo” tal como se creó con la llegada de Peregrino. Los veinte jóvenes, los primeros mestizos, afirman esto cuando ya han resumido los regalos y Peregrino les pregunta qué harán con el regalo que él les había dado:

-¿A quién le darán ustedes sus vidas?, pregunté.

-A la nueva tierra que le dio la vida a Pedro. (492)

Ahora es Peregrino el que pregunta a quién y qué darán. Ya disfruta del derecho de preguntar quizás porque él se ha dado cuenta de su papel como Dador y porque ha salido del círculo de la deuda. Los jóvenes devolverán el regalo de la vida a la tierra, así le permiten a Peregrino escapar del círculo. No obstante, si bien parece acabar o cerrarse el ciclo de deuda entre Peregrino y los veinte jóvenes, ya que ofrecen sus vidas a la nueva tierra, Peregrino no sigue el mismo orden temporal de ellos porque no tiene ninguna afiliación con ninguna tierra; es nómada, un marinero foráneo con el poder de entrar y salir del tiempo del mundo nuevo.

El poder del regalo de alterar la corriente del tiempo, por otra parte, no sólo se afirma por medio de los personajes y regalos de "El mundo nuevo". También Felipe y La Dama Loca, es decir el rey y la reina madre, reflexionan sobre este poder del regalo a la vez que explican el poderío que se gana al dar. En "El viejo mundo", la primera parte de la novela, La Dama Loca rescata al náufrago y le explica el motivo de su procesión fúnebre: quiere mostrar públicamente la posesión del cuerpo de su esposo difunto, Felipe el Hermoso, quien había tenido fama de ser muy infiel. De esta forma, ella se recompensa por lo mucho que sufrió por él. Al explicar esto, también hace referencia a la naturaleza del regalo:

\footnotetext{
Un verdadero regalo no admite una recompensa equivalente. Una ofrenda auténtica supera toda comparación y todo precio. Mi honor y mi rango, señor caballero, me impiden aceptar algo que, en contrapartida, pueda superar o siquiera equivaler a mi regalo: una corona o un cuerpo totales, finales, incomprables e incomparables. (80)
}

Para La Dama Loca el verdadero regalo es insuperable, ya que no admite reciprocidad. Tampoco se le puede poner un precio porque no se compara con nada; la comparación sería lo que determina su valor. En el caso del cambio de mercancías, el valor es determinado por medio de la comparación de una mercancía con otra. Pero, el "verdadero regalo” no puede tener equivalente y por eso tampoco puede ser superado. Rompe con toda relación circular, con todo trueque, lo que implica también una relación de poder: sólo el donante puede dar, el receptor tiene que aceptar el regalo y, en este caso, lo acepta pasivamente. Además, los señores no pueden recibir de sus subalternos, lo que se afirma hacia el final de la novela cuando Tiberio, el césar y antecedente de Felipe, manda ejecutar a un pescador que se atrevió a ofrecerle hospitalidad (684-5).

La Dama Loca afirma desde su lógica una característica fundamental del don: a saber, la indeterminación de su valor y significado, sobre todo su falta de sentido ante la muerte. 
Según esta última, el don suspende el tiempo y lo hace retroceder. La Dama Loca le explica al náufrago: “Olvidará usted todo esto que le he dicho. Todas mis palabras han sido dichas mañana. Esta procesión va en sentido opuesto al de ese tiempo que usted sabe contar. Venimos de la muerte" (80). La Dama Loca habla sobre el regalo precisamente porque ella está, o se siente, fuera del tiempo del náufrago. Como el don no tiene equivalente, el tiempo tampoco tiene medida para ella. Tanto La Dama Loca como Felipe, el rey, están obsesionados por superar y dominar al tiempo por medio de los regalos que otorgan y de los sacrificios.

El afán de La Dama Loca de afirmar su poderío a través del don es dudoso: para que un regalo sea "verdadero", no puede reconocerse como tal. Tanto el receptor como el donante deben olvidar e ignorar el regalo. Según el concepto radical de Jacques Derrida, no puede haber una recompensa y tampoco puede el don guardarse en la memoria. El momento en que el regalo se reconoce o aparece como tal, ya implica y simboliza un sacrificio o una estructura económica que anularía el regalo en el círculo ritual de la deuda (22-3). Esto se aplica a lo que Derrida califica de "los suplementos del don”: "el potlatch, las transgresiones y los excedentes, las plusvalías, la necesidad de dar o de devolver más, las devoluciones con usura, en una palabra: toda la sobrepuja sacrificial” (33).

A su vez, el regalo para Derrida es aneconómico; rompe con toda circularidad. Para indagar en la función de ruptura que el regalo ejerce en la narración, cabe aquí comentar un poco sobre la relación entre economía y narración. Junto a las leyes de distribución y partición, la economía también incluye el cambio y la circulación. Éstos se relacionan con la figura del círculo, figura con implicaciones profundas para cualquier narrativa económica. Como ha señalado Derrida el motivo de la circulación puede hacernos pensar que la ley de la economía es el retorno -circular- al punto de partida, al origen, también a casa (1618). En este sentido el destino de un individuo señala la reapropiación del lote, de un destino, del conocimiento de sí mismo, y de las tierras y propiedades. Esto sugiere la estructura odiseana de la narrativa. La Odisea concierne asegurar también la memoria del destino y de la propiedad de uno, es decir el otorgamiento de una herencia a un heredero. Telemakos busca a su padre en parte porque los pretendientes de Penélope malgastan la riqueza de Ulises y abusan de la hospitalidad de su casa. La narrativa odiseana involucra la figura del círculo tanto en el sentido del retorno como en el del reinicio de un ciclo. En Terra Nostra, sin embargo, cada nuevo ciclo implica una transformación; no empieza en el mismo lugar porque los espacios culturales de la novela se recodifican en la lectura. Zunilda Gertel afirma que en el texto de la novela los hechos históricos se re-codifican cíclicamente como la intertextualidad entre la voz narrativa y el lector, es decir como memoria cultural. Esta operación cíclica "no ofrece simplemente la forma del círculo sino de espiral, como alternancia en abierta disyunción, en proceso (memoria-olvido) hacia otra transformación” (Gertel 71-2). Mientras que la ley del trueque implica la circularidad y la alternancia cíclica de existencias, de vida y muerte, a lo largo de la novela los sacrificios, los regalos, las alternancias de existencias y las reiteraciones de hechos históricos interrumpen el flujo circular de estos ciclos en el mismo proceso que le obliga al lector a re-escribir los códigos culturales. Un nuevo ciclo puede comenzar, pero la renovación rige que no pueda empezar o terminar en el mismo lugar y tiempo. 
Las metáforas económicas del sacrificio, el potlatch, los regalos insuperables, el trueque y las deudas tanto sagradas como profanas predominan en Terra Nostra y con ellas la novela indaga en la lógica del don. "La parte maldita" que nos vincula, el don, sobre todo como escritura y palabra, también alimenta el deseo frustrado de la utopía en la obra de Fuentes. El autor revela este deseo en Cervantes, o la crítica de la lectura cuando pronuncia que "las cosas no son de todos y las palabras sí; las palabras son la primera y natural instancia de la propiedad común” (110). La tensión fundamental de la novela ilumina la violencia necesaria del regalo y de la escritura dentro del contexto de este deseo utópico. En este sentido, Terra Nostra nos muestra que hasta hablar del don implica una transgresión, la imposición forzosa de un significado, de una deuda y por ende una relación de poder.

Para concluir, la narración "El mundo nuevo" en Terra Nostra también funciona como potlatch, como un desafío al viejo mundo. De la misma manera que la leyenda del Viejo de las Memorias reta y transforma a su narratario Peregrino, éste al contar "El mundo nuevo" también desafía a su oyente, Felipe, el Señor. El tiempo narrativo de "El viejo mundo" sufre la incursión de otra historia que lo modifica, así transformándolo a "El otro mundo" en el que predominan la heterogeneidad y la confluencia de tiempos. También socava el poder de Felipe. Así que estas narraciones se ubican en una relación concéntrica, como en una caja china: un regalo (la leyenda del viejo) dentro de otro regalo mayor (la narración de "El mundo nuevo") dentro de la novela misma cuyo desafío se dirige a todos sus lectores: el reto de pensar de nuevo y de re-escribir la historia de Las Américas. Que sus lectores recobren las herencias múltiples de la América Latina y que recuerden la obligación de rescatar las herencias silenciadas durante siglos por la alianza entre el absolutismo y la modernización capitalista.

En Cervantes, o la crítica, cuando Fuentes caracteriza la escritura de Joyce como potlatch, no puede declarar a su propia obra como don o desafío, porque al hacerlo caería en la misma trampa de Felipe y La Dama Loca. Estos dos personajes, al contemplar la naturaleza del don, se limitan por el deseo de un retorno, de la recompensa — su regalos son interesados porque esperan adquirir el poder y también el dominio del tiempo. En una inversión hegeliana, se vuelven patéticos y esclavos de sus propias obsesiones. Por otra parte, cuando Fuentes declara que las palabras son la propiedad de todos, queda implícito el sacrificio de la sujetividad singular del autor: "Entonces, Miguel de Cervantes o James Joyce sólo pueden ser dueños de las palabras en la medida en que no son Cervantes y Joyce, sino todos: son el poeta. El poeta nace después de su acto: el poema. El poema crea a sus autores, como crea a sus lectores. Cervantes, lectura de todos. Joyce, escritura de todos” (110). Tal expropiación es natural para el regalo y para la escritura. Pero que un autor como Fuentes hable de tales autosacrificios, nos hace preguntar ¿qué recompensas espera este escritor? Desde luego, el nombre “Carlos Fuentes” había cobrado mucho prestigio por su obra previa y le garantizaba la venta de sus libros. Dado que Fuentes ha disfrutado de mucho éxito en el mercado internacional, es un poco irónico que sea él quien afirma el carácter expropiador del don en la forma de la escritura. No obstante, como escritor Fuentes ya participa en el campo del don y así se expone a las trampas del ciclo de endeudamiento. Si bien toda narrativa es regalo, con sólo escribir una novela nuestro autor juega en la frontera entre el don y el círculo de la deuda. 
La ostentación del potlatch de Fuentes, sin embargo, no debe conducirnos a un juicio reductivo acerca de sus intenciones, como su deseo de mostrar su proeza por ejemplo. Fuentes solamente participa en una competencia agresiva que paradójicamente infunde la solidaridad. Si bien se puede considerar a Terra Nostra un desafío al lector a que “produzca algo mejor”, también la novela rinde homenaje tanto a sus progenitores como a los contemporáneos de Fuentes — de aquí las referencias a personajes y figuras de las tradiciones hispanas e indígenas precortesianas, tanto como a los personajes de las obras de otros escritores del siglo veinte: Julio Cortázar, Jorge Luis Borges, Juan Rulfo, Gabriel García Márquez, Mario Vargas Llosa, para mencionar los más conocidos. No sólo funciona Terra Nostra como contrapartida, sino también como un gesto de gratitud que reconoce la deuda que tenemos por las múltiples herencias de México y España. Como un potlatch o un don ostentoso, Terra Nostra desafía al lector de esta manera: no busca realizar un trueque entre lector y escritor, sino que obliga al lector a reconsiderar la historia mutua de España y Latinoamérica, a enfrentar sus silencios y, finalmente, a reinventarse a sí mismo.

\section{Bibliografía}

Bataille, Georges. La part maudite, essai d'économie générale. Paris: Editions de Minuit, 1947.

Bourdieu, Pierre. The Logic of Practice. Richard Nice, trad. Stanford: Stanford Univrsity Press, 1990.

Derrida, Jacques. Dar (el) tiempo: I. La moneda falsa. Cristina de Peretti, trad. Barcelona: Paidós, 1995.

Fuentes, Carlos. Terra Nostra. México: Joaquín Mortiz, 1975. Cervantes, o la crítica de la lectura. México: Joaquín Mortiz, 1976.

Gertel, Zunilda. “Semiótica, historia y ficción en Terra Nostra”. Revista Iberoamericana 47/116-117 (1981): 63-72.

González Echevarría, Roberto. “Terra Nostra: Theory and Practice.” Carlos Fuentes: A Critical View. Robert Brody y Charles Rossman, eds. Austin: University of Texas Press, 1982. 132-45.

Levi-Strauss, Claude. Introduction to the Work of Marcel Mauss. Felicity Baker, trad. London: Routledge and Kegan Paul, 1950, 1987.

Mauss, Marcel. "Essai sur le don. Forme et raison de l'échange dans les sociétés archaiques”. Sociologie et anthropologie. Paris: PUF, 1950. 